\title{
Editorial
}

\section{NEEDING TO KNOW? ETHICAL DILEMMAS IN LEPROSY TREATMENT AND CONTROL}

\begin{abstract}
Summary A young man presents to your local clinic in a leprosy endemic country with a small patch of discoloured skin on his right forearm. The diagnosis is clear. You start to explain, but the man stops you: he doesn't want to hear more, just requests the medicine. But you are 'in conflict', and not just by the desire to discuss the situation more fully with your patient before prescribing a drug. The local public health team, of which you are a part, is currently evaluating the impact on the community's health of a patient education programme which necessitates informing all new leprosy cases of their diagnosis. What should you do? And can bio-ethics help?
\end{abstract}

\section{Control of leprosy}

This story will be familiar to many health care professionals who work in leprosy endemic countries. Clinically, the primary aim of intervention is to treat patients in order to achieve their cure, and to prevent the development of associated deformities. Broader objectives of leprosy control, however, are to interrupt transmission of the infection, thereby reducing the incidence of disease so that it no longer constitutes a public health problem. ${ }^{1}$ Prompt treatment of all existing and newly detected cases with multi-drug therapy (MDT) is the principal method currently used.

The most cost-effective approach for case-finding is the promotion of self-reporting of suspect lesions through increased community awareness about the disease and this requires the patient to be informed of the diagnosis. This approach should be supported by efficient and easily accessible treatment services for the community.

\section{Public health and the control of infectious diseases}

For those of us working in the field of public health, our role is to work together 'to provide the conditions in which people can be healthy'. ${ }^{2}$ Rather than simply focusing our attention on the individual, the patient above for example, our role is to also look at the health of the wider

Correspondence to: J. D. H. Porter (e-mail: John.Porter@lshtm.ac.uk)

The authors are directors of the International Programme in Ethics, Public Health and Human Rights, IPEPH, at the London School of Hygiene and Tropical Medicine) 
community, and decide how an individual case should be treated to provide the most benefit for the patient and for the community. A classical ethical dilemma in public health is whether to isolate an individual with an infectious disease - and therefore compromise his or her freedom - for the benefit of the population. This was the situation with leprosy before antibiotic treatment. In some countries, this approach has recently led to leprosy patients seeking compensation from the state for their 'draconian' treatment. ${ }^{3}$

Most situations are less clear cut than the classic textbook examples, and our man with the skin patch illustrates an important point. Public health interventions, like infectious disease control programmes, have the potential to embody an imbalance of power and capacity between the implementers and the recipients. ${ }^{4}$ Health professionals decide when and where to intervene. It is presumed that whatever harm the intervention may impose on individuals is outweighed by the good it will bring to the population as a whole. This form of practice, this perspective, often tends not to exemplify respect for the autonomy of the people at the receiving end of the intervention. ${ }^{5,6}$

So, what are the questions we should ask ourselves as health care practitioners when deciding whether to tell a person that he or she has leprosy? What are the issues that we need to confront in order to ensure that we treat the individual with dignity and respect? If a person is found early with a skin patch and no other signs of disease, is it necessary to inform him or her of the diagnosis? By simply taking treatment an individual will be cured, and not revealing the diagnosis reduces the likelihood of being stigmatized by the community.

\section{Ethics and principles}

Proponents of bioethics tell us that ethics can provide a useful structure to help address these complicated problems of right and wrong actions in clinical medicine and public health. Ethics is the systematic intellectual endeavour to guide one's conduct by reason - that is, to do what there are the best reasons for doing - while giving equal weight to the interests of each individual who will be affected by one's conduct. ${ }^{7}$

Within bioethics, the approach labelled 'principlism' has come to dominate current international thinking in clinical and public health ethics. Principlism asserts that any medicoethical dilemma, like the one above, can be tackled by reference to the following four principles: the principle of respect for autonomy (deliberated self-rule); the principle of beneficence (doing good); the principle of non-maleficence (doing no harm); and the principle of justice (fairness). The philosopher Raanon Gillon, an advocate of this system, has asserted that, along with attention to context, principlism provides a simple, accessible, and culturally neutral approach to thinking about ethical issues in health care. ${ }^{8}$

Using the four principles, a quick analysis of our case might look something like this. The autonomy of the patient needs to be considered and respected. According to the German philosopher Immanuel Kant, respect for autonomy means treating others as ends in themselves and never merely as means to some (externally defined) end. It is not therefore appropriate simply to treat and inform the patient in order to control leprosy in the community, or because leprosy needs to be eliminated. This is treating the patient as a means to a particular end. From this angle, any informed decision of the young man should be respected. But how has he come to his decision, and is it informed?

The principles of beneficence and non-maleficence identify a balance between the effort to help the person with leprosy and at the same time producing minimal harm. The traditional 
Hippocratic moral obligation of medicine is to provide beneficence with non-maleficence: net medical benefit to patients with minimal harm. Here, treating the man is beneficent (and has social utility in reducing leprosy in the community) but telling him the diagnosis would seem to inflict psychological harm, at least, and be against his wishes. The principle of justice refers to the fair distribution of society's burdens and benefits, and is perhaps least relevant of the principles to this case.

In the control of leprosy, a balance is needed between moral concern for the individual with the disease, and concern for the community in which the disease may spread. For public health practitioners there is a constant tension between the rights of the individual and the rights of the population. But these rights need to be balanced with correlative duties. For example, if the community has established a system for identifying a person with leprosy, then the community has a duty to ensure that individuals are treated with dignity, fairness, respect and compassion.

\section{Context and stigma}

Leprosy is now a disease that can be treated and cured, but it is stigmatized. ${ }^{9}$ It is surrounded by myth, by fear, and by isolation. So, as more is discovered and understood about the condition, it would appear correspondingly important to engage communities in a process of discussion and education about leprosy, with the overarching goal of reducing the stigma surrounding it. In each community, however, there is a different understanding of leprosy, different educational information, and different perspectives on how to control the disease with the minimum of harm to the patient.

With this in mind, it becomes clear that the approach of principlism, although helpful, is also somewhat simplistic. The relationship between the health care professional and the patient is central to the story and, of course, needs to be balanced, open, and to take account of the potential imbalance of power between the patient and health care worker. But this relationship itself must be placed, and understood, within the context of who the patient is, his or her knowledge of the disease, the stigma in the community, as well as the health care systems established to support that person during treatment and rehabilitation. If there are no support structures, then it may not be appropriate to simply tell the person that he or she has leprosy.

Ethical considerations are relative to the context in which they appear. While there is no easy solution to the case provided, there can be little doubt about the efforts needed to reduce the stigma of leprosy, and to create an environment in which informing the patient becomes an acceptable moral norm.

*Department of Infectious and Tropical Diseases and

JOHN D. H. PORTER*,**

**Department Public Health and Policy, ANTHONY S. KESSEL**

London School of Hygiene and Tropical Medicine, Keppel Street, London WCIE 7HT, UK

\section{References}

1 Noordeen SK, Pannikar VK. Leprosy. In: Cook GC (ed) Manson's tropical diseases. Saunders, London, 1996.

${ }^{2}$ Institute of Medicine. Future of public health. National Academy Press, Washington DC, 1988, pp 1-7. 
${ }^{3}$ World News. Lepers win pay-out for decades in isolation. Independent, May 24, p. 20, 2001

${ }^{4}$ Porter JDH, Ogden JA. Ethics of directly observed therapy for the control of infectious diseases. Bull Inst Pasteur, 1997; 95: 117-127.

5 Skrabanek P. Why is preventative medicine exempted from ethical constrains? J Med Ethics, 1990; 16: $187-190$.

${ }^{6}$ Hall SA. Symposium on ethics and public health: should public health respect autonomy? J Med Ethics, 1992; 18: 97-201.

7 Rachels J. The elements of moral philosophy, 3rd edition. McGraw Hill, New York, 1999.

8 Gillon R. Medical ethics: four principles plus attention to scope. BMJ, 1994; 309: 184-188.

9 Ogden JA, Porter JDH. Leprosy: applying qualitative techniques to research and intervention. Lepr Rev, 1999; 70: 129-135. 